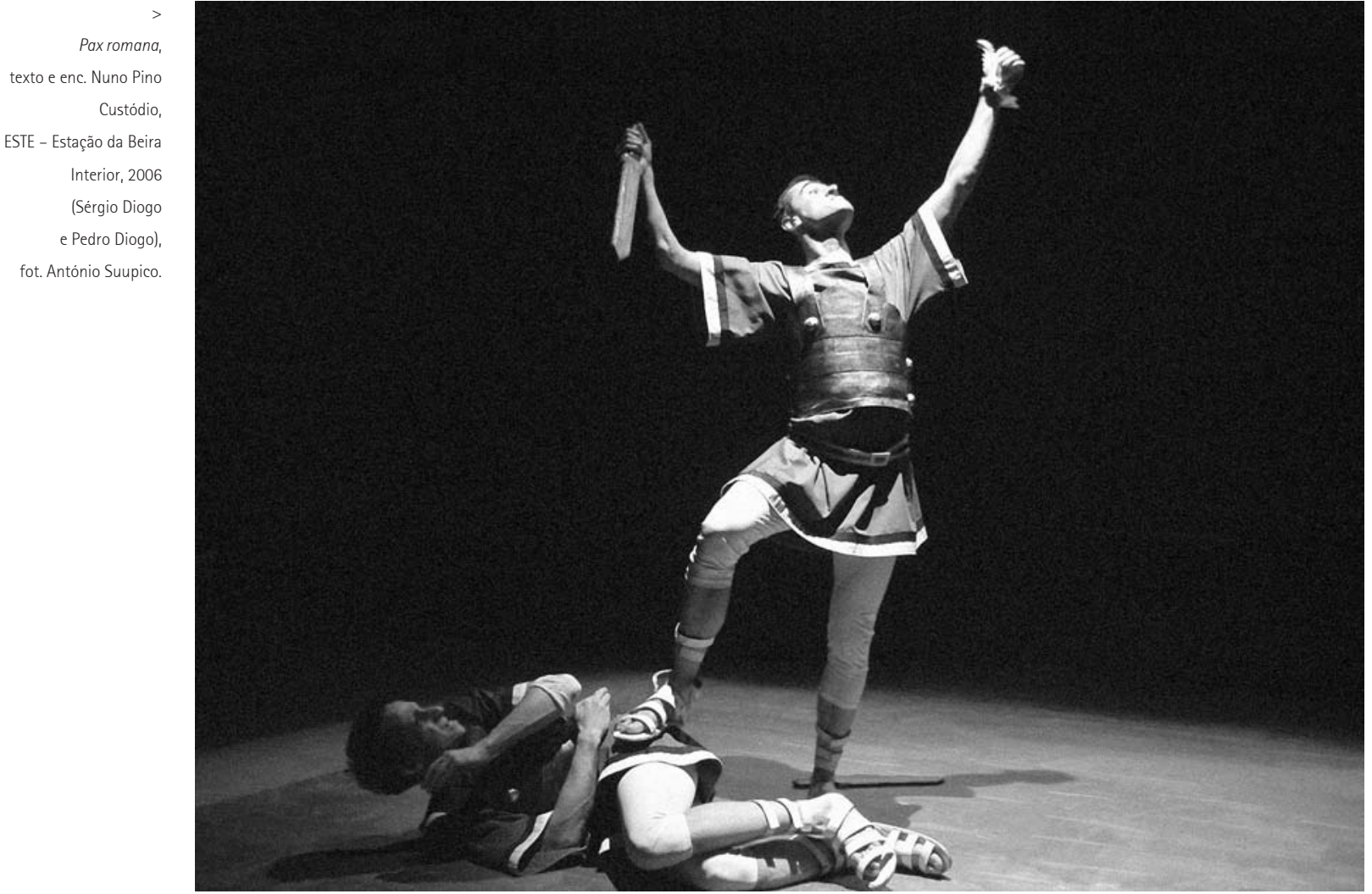

\title{
Paz e guerra com humor crítico
}

\section{Maria Helena Serôdio}

Titulo: Pax romana (2006). Dramaturgia e encenação: Nuno Pino Custódio. Música: Fernando Mota. Figurinos: Marta Carreiras / ESTE. Equipamento bélico: Nuna Elias (Aprendiz de Feiticeiro). Desenho de luz: César Fortes e Pedro Fino. Interpretação: Alexandre Barata, Pedro Diogo e Sérgio Fernandes. Produção: ESTE - Estação Teatral da Beira Interior. Local e data de estreia: Auditório da Escola Secundária do Fundão, 4 de Maio de 2006.

No Castelo de S. Jorge a 1 de Setembro de 2006, de 8 a 11 de Março de

2007 no Chapitô.

Para o João C., no seu $6 .^{\circ}$ aniversário

Há dois anos em cena - na forma ambulante e pouco noticiada pela imprensa de referência como costuma ser o destino das companhias que trabalham fora das grandes cidades -, o espectáculo da ESTE (Estação Teatral da Beira Interior) dá um testemunho expressivo do valor artístico de alguns dos projectos que tomam forma em lugares "descentrados". Circulou pontualmente por Lisboa', é certo, mas poucos terão sabido da sua passagem. Numa dessas vezes, a cena foi implantada no largo do castelo de S. Jorge - durante o Festival de Máscaras e Comediantes que Filipe Crawford organiza - o que Ihe acrescentava o prazer da cena ao ar livre e uma nada excêntrica ligação ao lugar, onde se desenrolava o espectáculo, pela temática da paz/guerra que a peça tão esplendidamente satiriza. Entretanto, e felizmente, a carreira do espectáculo prossegue e algumas andanças mais estão já prometidas, como regista a agenda da companhia, desta vez para os Açores e a Galiza.

0 que mais impressiona neste espectáculo é a extraordinária integração de todos os seus elementos para a criação de um objecto artístico exigente na qualidade e, ao mesmo tempo, de uma notável comunicabilidade.
0 registo dominante é o cómico que busca na técnica de Commedia dell'Arte o seu suporte principal (no trabalho da máscara facial - que não obriga ao uso de um artefacto que tape total ou parcialmente a cara do actor - e na expressividade do corpo), mas percebe-se o muito que se Ihe acrescenta de forma preciosa: no "texto", nas sonoridades, na citação da banda desenhada (nomeadamente nos figurinos e composição dos "romanos" que nos reporta aos livros do Asterix), nas marcações, nos tempos e, enfim, num vasto número de cuidados que se percebem na ordenação maior da cena que é,

fundamentalmente, da responsabilidade de Nuno Pino Custódio.

Na carreira - de já mais de 16 anos - deste jovem encenador ${ }^{2}$ encontramos clássicos da dramaturgia contemporânea (como Cocteau e Beckett) no início da sua carreira no Teatro Experimental A Barca, que criou e dirigiu em 1991. Nessa altura já passara por uma aprendizagem da "técnica" da Commedia dell'Arte com Filipe Crawford - que considera seu Mestre - e, curiosamente, como Nuno Pino Custódio reconhece, o trabalho sobre $A$ voz humana e Dias felizes já foi 

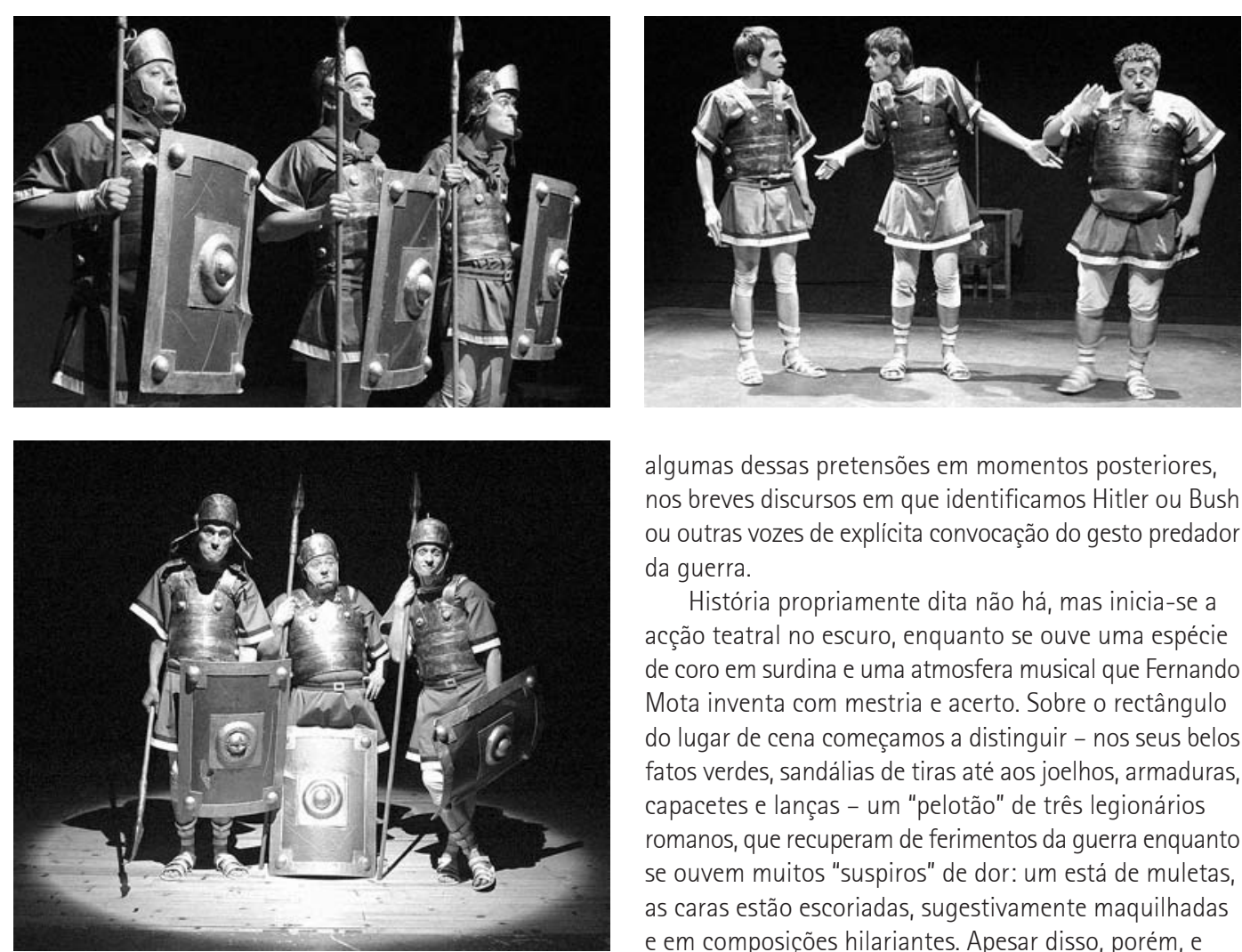

consequência dessa aprendizagem, mas num sentido de procurar um caminho mais pessoal. No espectáculo que encena em 1993 - Pretextos e acidentes - avança um pouco mais nesse percurso de experimentar em situação de encenação a mesma "técnica" que tinha adquirido aparentemente como ferramenta para a improvisação.

Essa aprendizagem e a procura de um caminho próprio têm passado por outras experimentações e outros desafios. Foi o caso, notável a vários níveis, do texto que escreveu e interpretou (dirigido por Miguel Seabra e no contexto do Teatro Meridional) - O relato de Alabad (2002) ${ }^{3}$ - sobre a conquista de Lisboa pelos cristãos, mas perspectivada pelo "outro lado", o dos vencidos, numa visão inteligentemente emotiva, a que não faltava algum humor depurado, próximo do que está, afinal, na base da própria Commedia dell'Arte. É, de resto, nesse registo que Nuno Pino Custódio tem trabalhado com o Teatro Meridional, quer em treinos específicos, quer na construção de máscaras e, num caso muito particular, na encenação de um texto muito complexo de Sinisterra - O grande teatro de Oklahoma (em 2005) - sobre textos de Kafka, uma experiência elaborada e complexa, com algumas imagens expressivas e momentos fortes, mas de uma mais dificil comunicabilidade.

No caso desta Pax romana, e no contexto da companhia que agora dirige no Fundão, Nuno Pino Custódio regista uma excepcional criação cénica que dá testemunho de um trabalho sério, meditado, culto, de candente actualidade, apresentado-a, todavia, de uma forma cómica, quase ligeira, embora com um indiscutivel rigor no gesto, no movimento e em muitos outros aspectos da sua materialização cénica. Trata-se de usar um contexto "cultural" - da Roma imperial - para, num dos seus "fragmentos" da "máquina de guerra", desconstruir poses de autoridade, ridicularizar pretensões e, sobretudo, rever algumas dessas pretensões em momentos posteriores, nos breves discursos em que identificamos Hitler ou Bush ou outras vozes de explícita convocação do gesto predador da guerra.

História propriamente dita não há, mas inicia-se a acção teatral no escuro, enquanto se ouve uma espécie de coro em surdina e uma atmosfera musical que Fernando Mota inventa com mestria e acerto. Sobre o rectângulo do lugar de cena começamos a distinguir - nos seus belos fatos verdes, sandálias de tiras até aos joelhos, armaduras, capacetes e lanças - um "pelotão" de três legionários romanos, que recuperam de ferimentos da guerra enquanto se ouvem muitos "suspiros" de dor: um está de muletas, as caras estão escoriadas, sugestivamente maquilhadas e em composições hilariantes. Apesar disso, porém, e mesmo longe do que seria o campo militar, Maximus, Tulius e Caius persistem teimosamente nos treinos. 0 primeiro, barrigudo e de cara entumescida, é quem dá (ou quer dar) o treino, mas tudo aquilo acaba por parecer desconexo e absurdo, algo entre os irmãos Marx, Charlot ou Woody Allen no seu melhor. Um permanente linguajar de "latinorum" (alguns estupidus, canastronem, falhatum, ego individualis, etc.), o desencontro entre as ordens e o seu cumprimento, o desacerto dos passos à esquerda ou à direita, pequenos gestos de desobediência, muitos "Ave, Caesar", uma pretensa luta de gladiadores à espera do polegar para cima ou para baixo (enquanto não vem a ordem, o vencedor limpa as unhas com o facalhão de madeira...), e a tenebrosa - mas aqui dita de forma mais ou menos desprendida - frase de Suetónio com que os gladiadores saudavam o imperador "Ave, Caesar, moriturite salutant" (Salve, César, aqueles que vão morrer saúdam-te).

É, por muitas razões, um trabalho exemplar: de rigor na composição do gesto, movimento e expressão facial; de imaginação delirante na linguagem inventada; de "reconstrução" criativa do vestuário romano (desenho brilhante da Marta Carreiras); de inventiva criação de sonoridades vocais e musicais; de acertadissimo compasso na ridicularização da guerra e dos "treinos" militares; no jogo magnífico que empreende com os espectadores.

Se a expressão de Karl Valentin - de que o teatro deveria ser obrigatório - pode ter alguma validade acertada é com este espectáculo: é para maiores de 6 anos, mas não haverá nenhum adulto que, ao ver este espectáculo, não sinta ter regressado também ao olhar de pura alegria dessa idade. Essa obrigação deveria ser para cumprir.
<

Pax romana, texto e enc. Nuno Pino Custódio, ESTE - Estação da Beira Interior 2006 (<Alexandre Barata, Pedro Diogo e Sérgio Fernandes; > Pedro Diogo, Sérgio Fernandes e Alexandre Barata; $\checkmark$ Sérgio Fernandes, Alexandre Barata e Pedro Diogo), fot. Ricardo Brito. The
3 Embora exista um texto policopiado desta peça, é lamentável não ter sido ainda publicada, o que a deixaria mais disponivel para outras realizações teatrais. 